\title{
Reflectance Spectra Measurements of Mt. Etna: A Comparison with Multispectral/Hyperspectral Satellite
}

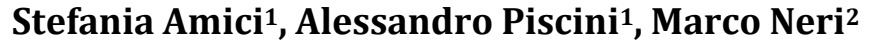 \\ ${ }^{1}$ Istituto Nazionale di Geofisica e Vulcanologia, Centro Nazionale Terremoti, Roma, Italy \\ ${ }^{2}$ Istituto Nazionale di Geofisica e Vulcanologia, Sezione di Catania, Osservatorio Etneo, Catania, Italy \\ Email: stefania.amici@ingv.it, alessandro.piscini@ingv.it, marco.neri@ingv.it
}

Received 19 September 2014; revised 15 October 2014; accepted 10 November 2014

Copyright (C) 2014 by authors and Scientific Research Publishing Inc.

This work is licensed under the Creative Commons Attribution International License (CC BY).

http://creativecommons.org/licenses/by/4.0/

(c) (i) Open Access

\begin{abstract}
We present a collection of eight reflectance spectra representative of Mt. Etna volcano lava flows. The reflectance spectra were measured with a FieldSpecPro from $350 \mathrm{~nm}$ to $2500 \mathrm{~nm}$ during a fieldwork in June 2007. The reflectance has been compared with reflectance obtained by multispectral Advanced Space borne Thermal Emission and Reflection Radiometer (ASTER) and by hyper spectral E01-Hyperion satellites. Prior the comparison, reflectance spectra have been convolved with ASTER and E01-Hyperion spectral functions. The results show percentage errors in accordance to those present in literature in the ASTER SWIR range. However, some differences have been confirmed for the ASTER reflectance product (ASTER_07) in visible channels. Regarding E01-Hyperion, a good agreement of reflectance against field measurement has been found resulting in 5\% percentage maximum error in the VIS and up 30\% in SWIR spectral range. The capacity of reproducing spectral feature by E01-Hyperion has been checked on bright pixels (ice-snow) in the acquired image.
\end{abstract}

\section{Keywords}

ASTER, E01-Hyperion, FieldSpecPro, Etna, Imaging Spectroscopy

\section{Introduction}

Spectral reflectance plays an important role in visible and short wavelength infrared (VIS-SWIR) remote sensing. Each material inorganically and organically absorbs and reflects the incoming radiation in a very peculiar way [1]. In the $0.4-2.5 \mu \mathrm{m}$ range, minerals display absorption features due to the interaction of light with 
anions (Fe, Mg, $\mathrm{Al})$ and cations $\left(\mathrm{OH}, \mathrm{H}_{2} \mathrm{O}, \mathrm{CO}_{3}\right)$. Organic compounds including vegetation display diagnostic absorbent features that occur in and typify healthy and alternated state of vegetation [2].

Reflectance spectra provide information about the specific material and their composition. They are used for different applications such as: classification of remote sensed data, identification of mineral features of rock, vegetation mapping, etc. [3] [4]. The interest in reflectance spectra of volcanic rocks is recently increasing as they can play an important role as planetary analogues [5]-[7]. In fact, these spectra can be used to identify compounds by data acquired by ongoing solar system exploration missions [8] [9].

In addition, spectra measured in field trace the variation observed in soil, rock, etc. compared to measurements of samples collected in laboratory. Furthermore, the infield reflectance spectra acquired near the contemporaneous satellite passage are used for vicarious calibration [10].

At satellite scale, multispectral sensors such as ASTER have been used in many fields including mineral mapping and hydrothermal alteration [11]-[13] and geomorphology [14].

A step forward was reached in the last decades thanks to imaging hyper spectral sensors on board of satellite which combined the spectroscopy information to a wide area.

Hyper spectral images acquired by satellites, such as EO1-Hyperion, have been intensively used for quantifying agricultural crops, modeling forest canopy biochemical properties, detecting crop stress and disease, mapping leaf chlorophyll content [15], and for predictions of soil organic carbon [16].

Now multispectral and hyperspectral sensors are routinely applied to geomorphologic, geological and geophysical investigations [17]-[20].

The current paper presents eight reflectance spectra acquired on several surfaces of Mt. Etna volcano including different age lava flows and snow-ice which, in certain cases, can be used to validate reflectance measurements from sensors such as ASTER and EO1-Hyperion.

The study is organized as follows: Session 2 includes the study area, the instrument and the reflectance measurements; Session 3 summarizes the results and Session 4 presents the conclusions.

\section{Methods}

\subsection{Study Area}

Mt Etna is a very active mugearitic-hawaiitic strato-volcano located in eastern Sicily, Italy $\left(37^{\circ} 44^{\prime} 33^{\prime \prime} \mathrm{N}, 15^{\circ} 0^{\prime} 16^{\prime} \mathrm{E}\right)$. It has a $3329.6 \mathrm{~m}$ elevation and a radius of about $\sim 18 \mathrm{~km}$. Its flanks are mostly covered by recent lava flows. The volcano rests on a sedimentary substratum composed of Tertiary flysch units belonging to the AppenninicMaghrebian Chain, to the $\mathrm{N}$ and $\mathrm{W}$, and of Quaternary sands and clays of the Catania basin on the other side [21] [22]. Mt. Etna is characterized by very frequent lava eruption, gas emission and Stromboli an activity. Due to its activity the volcano is consequently exposed to resurfacing processes, which might change the spectral features [23]-[25]. On the other hand, the areas of the volcano, which are not interested by resurfacing processes, may vary their spectral features due to alteration processes or vegetation growth. The most common lava type on Mt. Etna is ' $a$ 'ā, which is characterized by a rough edge shape different from that of the pāhoehoe type, which is characterized by a cordon shape. Figure 1 shows the historical lava flows which are selected for the in situ measurements. A detailed description of the eruptions associated with the lava flows can be found in [26]-[28].

\subsection{In Field Reflectance Acquisitions}

Reflectance measurements were collected with a ADS FieldSpecPro ${ }^{\circledR}$ instrument (or briefly FieldSpec). This is a portable, battery powered, spectroradiometer [29], operating in three detector ranges, 350 - $1050 \mathrm{~nm}, 1000$ $1800 \mathrm{~nm}, 1800$ - $2500 \mathrm{~nm}$, by using three spectrometers, incorporated into a single instrument. A three-step measurement protocol was developed for the FieldSpec: 1) pre-campaign activity; 2) field protocol; 3) postcampaign instrumental controls as described in [10].

The reflectance spectra of the selected surfaces were obtained automatically by the instrument software as the ratio of the target radiance and of a standard white reference (Spectralon), multiplied by the Spectralon absolute spectral reflectance. Dark current and white reference were taken before each reflectance measurement; in this way, illumination variations between the measurement of the target and of the reference can be avoided [30] [10]. Each spectrum consists of an average of 40 individual spectra, collected between 11:00 - 14:00 local time 


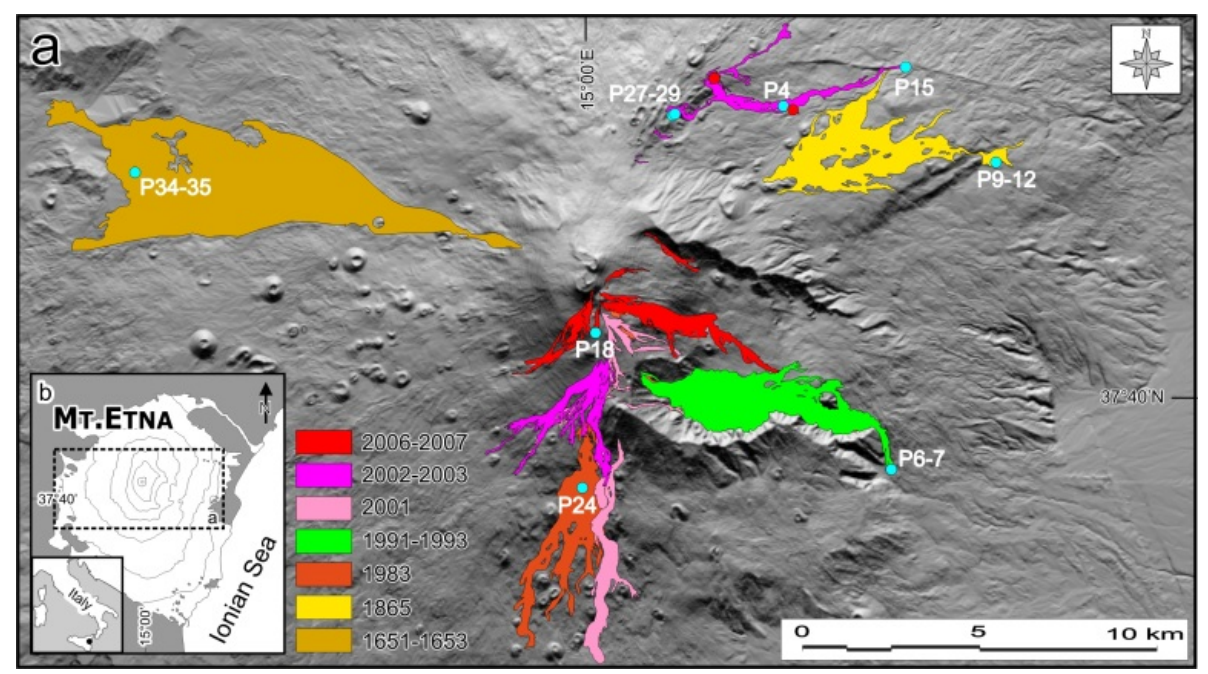

Figure 1. Sampled historical lava flows of Mt. Etna over a DEM; light blue circles indicate the location of in situ spectral reflectance measurements.

under clear-sky conditions, calm wind. and covering an area representative of satellite pixel. The maximum standard deviation throughout the spectrum is 0.05 .

\subsection{Satellite Data: ASTER and E01-Hyperion}

On demand acquisition of ASTER in the campaign time frame (17 - 21 June 2007) was requested. Image data of good quality and cloud free was acquired on 19 June 2007 at 9:59 GMT.

ASTER has three bands in the Visible-Near Infrared region (VNIR) six bands in the Short Wave Infrared region (SWIR) and four bands in the Thermal Infrared Region (TIR) wavelength region [31]-[35]. All ASTER images are supplied as georeferenced products, created by performing geometric and radiometric corrections on the original Level 1A image data and a re-projection onto a rotated "path oriented" map at full instrument resolution. The $3 \sigma$ registration accuracies for SWIR/VNIR were 0.054 SWIR pixels and 0.051 SWIR pixels in the cross-track and the along-track directions respectively [36] [37]. The AST_07 L2 [38] reflectance product covering the volcano Etna was used. AST_07 contains surface reflectance for each of the nine VNIR and SWIR bands at 15-m and 30-m resolutions, respectively [38]. Pre-processing of the ASTER data consisted of resampling VNIR bands to the SWIR $30 \mathrm{~m}$ spatial resolution and combining the VNIR and SWIR data into a 9-band surface reflectance image cube.

Hyperspectral data were acquired by EO1-Hyperion just one month later the campaign. The Hyperion sensor covers the wavelength region from 400 to $2500 \mathrm{~nm}$ with 220 bands of at $10 \mathrm{~nm}$ spectral resolution and $30 \mathrm{~m}$ spatial resolution [39]. The sensor was designed as a technology demonstrator rather than a scientific driven mission. It is not equipped with an on board calibration unit and has a very low signal to noise ratio (SNRVNIR $550-700 \mathrm{~nm}=140-190$, SNRSWIR $\sim 1225 \mathrm{~nm}=96$, and SNRSWIR 2125nm = 38) which limit its performance. Furthermore no standard products are provided and the whole calibration chain has to be applied including geo-correction.

The first step of the Hyperion data pre-processing consisted of eliminating uncelebrated bands. The Level 1 Radiometric product has a total of 242 bands, but only 198 of these are calibrated [40]. There are only 196 unique channels, due to an overlap between the focal planes of VNIR, band $56(915.23 \mathrm{~nm}), 57(925.41 \mathrm{~nm})$ and SWIR, band $77(912.45 \mathrm{~nm}), 78$ (922.54 nm). All uncelebrated bands, as well as bands 77 and 78, were removed before further processing, and a scaling factor of 40 and 80 was applied, respectively, to the VNIR and SWIR bands to obtain the $\mathrm{W} / \mathrm{m} 2 / \mathrm{sr} / \mu \mathrm{m}$ [41]. A small number of Hyperion's detectors are malfunctioning, which often results in vertical striping in the image across all bands. The striping effect was removed by replacing bad values with the average of the good values on either side of them. Surface reflectance was retrieved using the Fast Line-of-sight Atmospheric Analysis of Spectral Hypercubes [41] [42] algorithm as developed in the FLAASH ENVI module [42]. The parameters for ENVI FLAASH include entering information about the collecting sensor 
and the collected scene, selecting an atmosphere and aerosol model for the correction, and setting the options for the atmosphere correction model.

We selected a Mid Latitude Summer Atmospheric model in order to characterize the water vapour present in the atmosphere. The aerosol type selected was the rural one in accordance with the Mt. Etna scenario, not strongly affected by urban or industrial sources [42]. Finally, the Hyperion reflectance image was geocoded by using Ground Control Points taken from the ASTER image. The reflectance spectra obtained for the selected area was smoothed to reduce spectral artifacts by using an adjacent averaging filter with pointing window equal 7.

\section{Results and Discussion}

\subsection{Reflectance Measurements from FieldSpecPro ${ }^{\circledR}$}

Reflectance spectra were acquired in correspondence of 12 surfaces (Table 1), including 7 hystorical lava flows (Figure 1). Ice/snow reflectance was measured on the top of the volcano (Torre del Filosofo site, Table 1, $\left.37^{\circ} 44^{\prime} \mathrm{N}, 14^{\circ} 60^{\prime} \mathrm{E}\right)$.

All spectra (Figure 2) show two gaps respectively at around $1400 \mathrm{~nm}$ and $1900 \mathrm{~nm}$ due to the removal of the noise caused by atmospheric water vapor in these bands. In general, the acquired reflectance shows the typical trend of basaltic rock, which characterizes Mt. Etna's lava flows.

Low absolute reflectance values (maximum value between $0.04-0.07$ ) have been measured in the younger lava flows (2002 and 2007) in accordance with [25] [43]. Higher reflectance values (max ranging between 0.25 0.15) have been measured in 1652, and 1992 lava flows due to lichens. 1992 lava flow reflectance (p6-1992) shows lichen alteration feature for wavelength greater than $650 \mathrm{~nm}$ and spectral mixing effect between $400-700$ $\mathrm{nm}$ (p7-1992) because of the lichens don’t completely mask the underlying rock. Two different classes, scoriaceous lava with reddish oxidation, and small bushes were measured in 1865 lava flow (p9-1965, p12-1865).

\subsection{ASTER vs in Field Measurement}

In ground, reflectance (P18-2006) measured in correspondence of ASTER passage was resembled by computing the convolution with the ASTER relative spectral response function. In Figure 3, the comparison between ASTER and the corresponding in situ reflectance, convolved with the ASTER response function, is shown.

Table 2 shows the error percentages of the ASTER measurements, compared to the reference reflectance measurements. Minor percentage errors are found in the SWIR (min 2.4\% to max 18.8\%), probably due to the decrease of aerosol spectral absorption with wavelength [44]. In the SWIR range, the comparison shows an average percentage error between $2.4 \%-6.0 \%$ for the first 4 SWIR bands and a higher value for the 5th band $(2500 \mathrm{~nm})$ equal to $18 \%$ in the SWIR range for point p18 acquired during the ASTER passage. This value is in agreement with the ASTER error in this range [45].

\subsection{E01-Hyperion vs in Field Measurement}

The comparison between EO1-Hyperion reflectance with the spectrum acquired in the p18 is showed in Figure 4(a). The estimated percentage error is shown in Figure 4(b). The better spectral performance is in the visible range between $500 \mathrm{~nm}$ and $800 \mathrm{~nm}$ with a maximum percentage error of $5 \%$ while a maximum percentage of $30 \%$ is in SWIR range.

\subsection{Spectral Features for Bright Target: Ice-Snow}

\subsubsection{ASTER: Ice-Snow Reflectance Comparison}

In Figure 5, the Field Spec snow/ice is compared respectively to the corresponding ASTER reflectance spectrum (p27-ASTER) A good spectral correspondence in the overall shape is found.

The observed drop in the reflectance may be interpreted as melting effects. In fact, when snow melts, there is more radiation being absorbed by the snow pack. This produces a positive feedback, causing further melt and thus further decreases in alb do [46]).

The visible band 2 (Figure 5) shows a depletion of reflectance compare to an expected reflectance maximum to confirm the hypothesis an atmospheric correction issue of ASTER_07 product in the visible bands. 
Table 1. Features measured sites.

\begin{tabular}{lccc}
\hline Date & & & Measured surfaces features \\
\cline { 2 - 3 } $17-06-2007$ & ID & Surface & Description \\
$18-06-2007$ & p4 & Lava flow 2002 & Fresh scoriaceous lava \\
$18-06-2007$ & p6 & lava flow 1992 & Lava covered by lichen \\
$18-06-2007$ & p7 & Lava flow 1992 & Fresh scoriaceous lava partially covered by ash \\
$18-06-2007$ & p9 & Lava flow 1865 & Scoriaceous lava with reddish oxidation \\
$18-06-2007$ & p12 & Lava flow 1865 & Lava covered by lichens \\
$19-06-2007$ & p15 & Lava flow 2002 & Not-welded scoriae at the front of the lava flow \\
$19-06-2007$ & p18 & Ash fallout 2007 & 2007 ash covering 2006 lava flow \\
$20-06-2007$ & p24 & Lava flow 1983 & Surfaces with pahoehoe morphology \\
$20-06-2007$ & p27 & Snow ice & Torre del Filosofo \\
$21-06-2007$ & p29 & Lava flow 2002 & Lava and welded scoriae cropping out close to the eruptive vent \\
$21-06-2007$ & p34 & Lava flow 1652 & Surfaces with pahoehoe morphology covered by lichens \\
$17-06-2007$ & p35 & Lava flow 1652 & Pāhoehoe Lavas characterized by undulating and ropy surfaces \\
$18-06-2007$ & p4 & Lava flow 2002 & covered buy mosses and lichens \\
$18-06-2007$ & p6 & Lava flow 1992 & Fresh scoriaceous lava \\
$18-06-2007$ & p7 & Lava flow 1992 & Lava covered by lichen \\
\hline & p9 & Lava flow 1865 & Fresh scoriaceous lava partially covered by ash \\
\hline
\end{tabular}
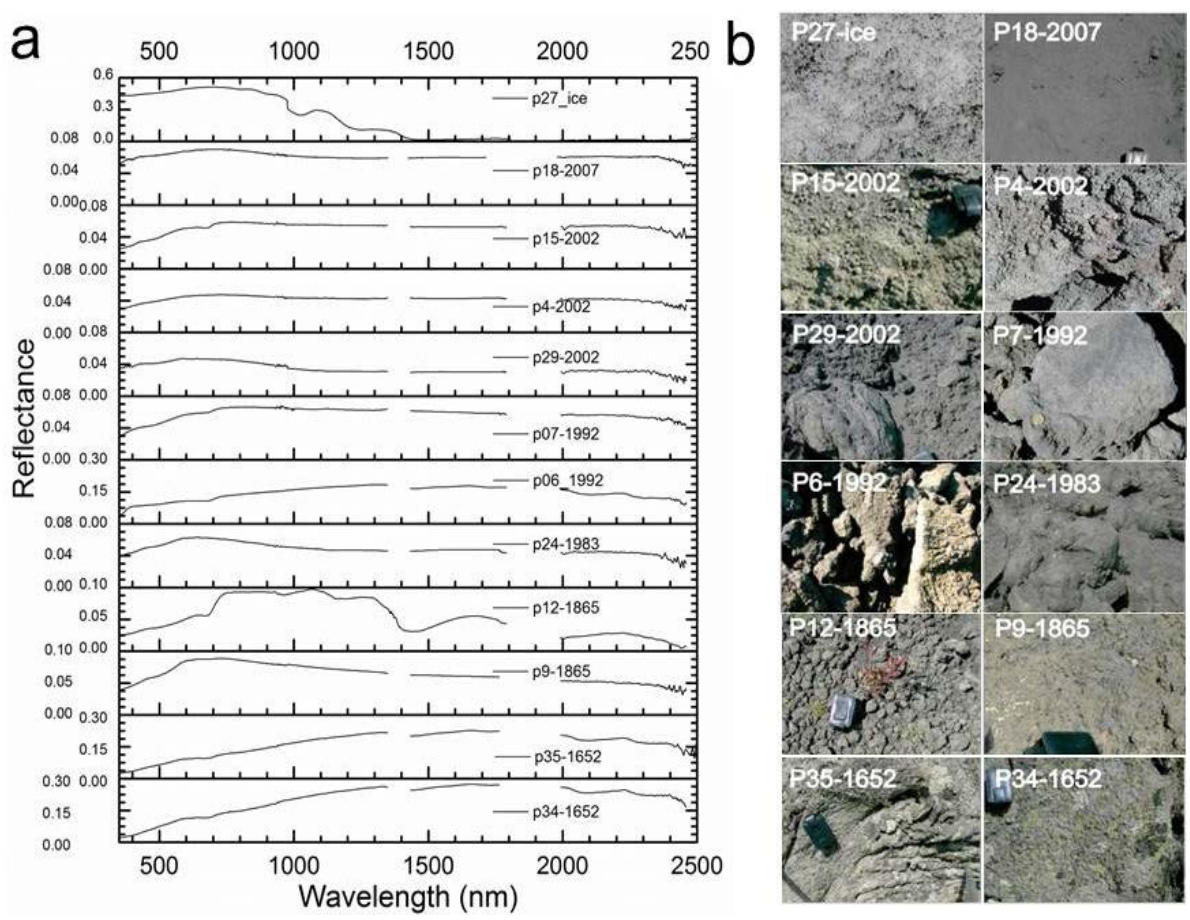

Figure 2. (a) Surface reflectance of different historical Etna lava flows measured with the FieldSpec Spectrometer. The atmospheric absorption bands dominated by noise have been removed; (b) Pictures of the surfaces are shown. Reflectance of exposed lava and lava plus reddish bushes (1865) and lava and lava with lichens (1992) have been measured representing different endmembers.

Furthermore, the reflectance in SWIR bands appears to be higher than the reference. An interpretation for this may be a combined effect of not very thick ice layer (rock underneath) and the pixel mixed reflectance that includes the ice-snow and volcanic surface. 


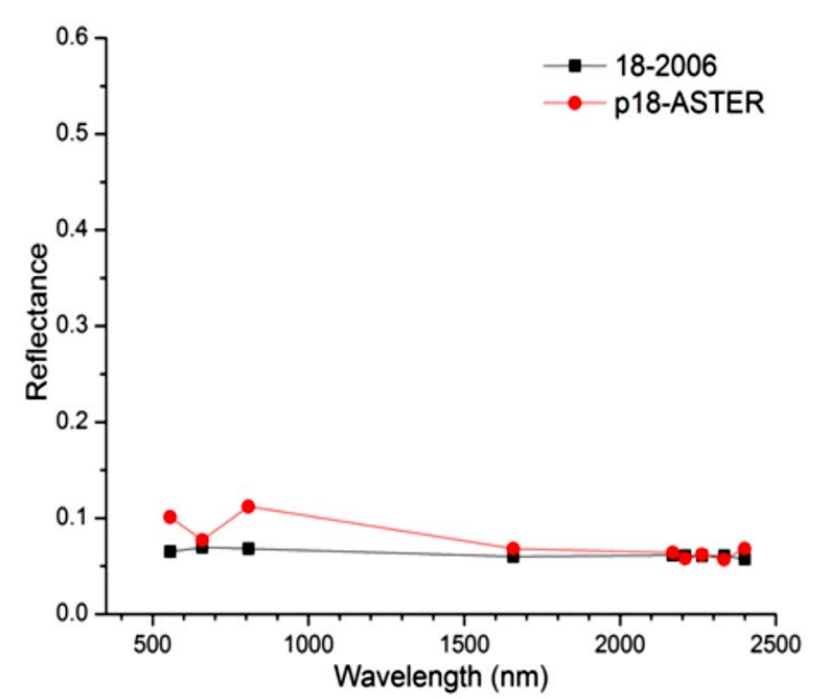

Figure 3. ASTER surface reflectance (red) and ASD (black) spectra convolved using VNIR/SWIR ASTER response functions for ash measurement (site p18).
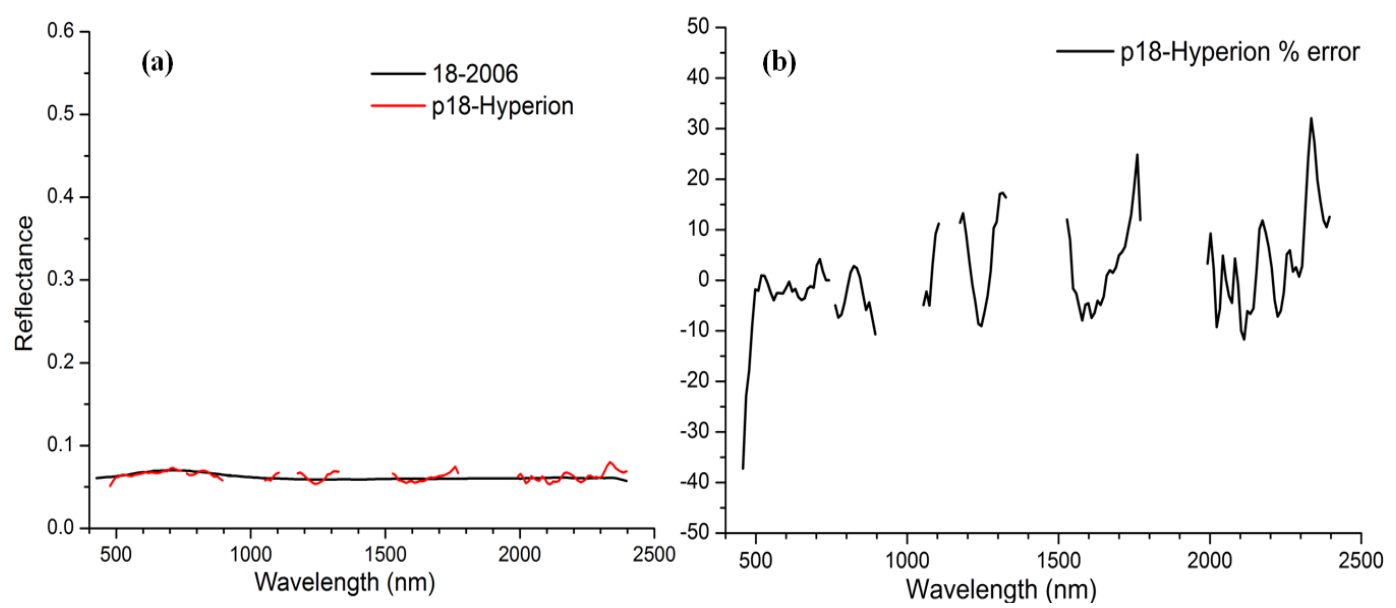

Figure 4. (a) The graph shows in situ reflectance spectrum (p18) compared to the satellite one (p18-Hyperion); (b) The graph shows the EO1-Hyperion spectral percentage error for p18.

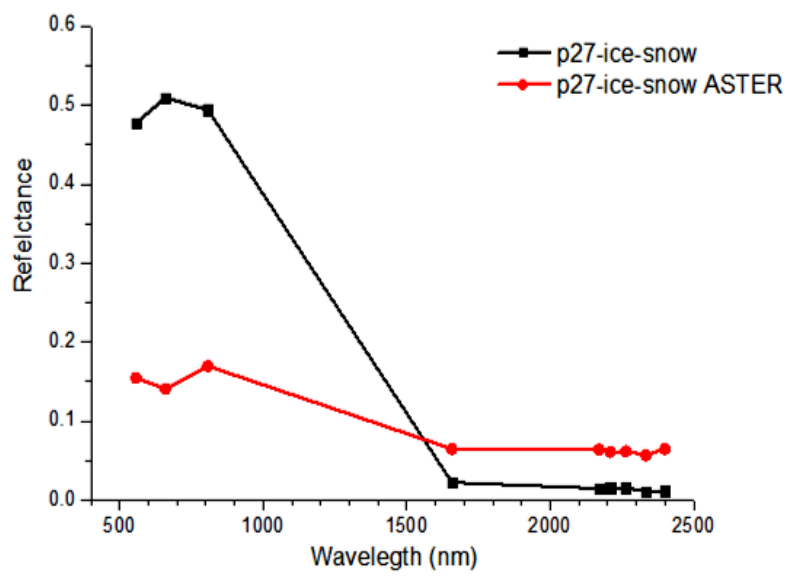

Figure 5. ASTER surface reflectance (red) and ASD (black) spectra convolved using VNIR/SWIR ASTER response functions for ash measurement (site p27). 
Table 2. Features measured sites.

\begin{tabular}{cc}
\hline \multirow{2}{*}{ ASTER Bands $(\mathrm{nm})$} & [(ASTER-Reference)/Reference] $\times 100$ \\
\cline { 2 - 2 } 556 & $\boldsymbol{p 1 8}$ Percentage Error \\
659 & 54.79402 \\
807 & 10.63981 \\
1657 & 63.97763 \\
2169 & 13.69203 \\
2209 & 4.56884 \\
2263 & -4.40338 \\
2334 & 2.37392 \\
2400 & -6.03131 \\
& 18.76879 \\
\hline
\end{tabular}

\subsubsection{E01-Hyperion: Ice-Snow Reflectance Comparison}

EO1-Hyperion has a very low SNR (up 150 in VIS and 100 SWIR, [47] which makes very hard to get spectral information from very low reflectance surfaces, like basalts.

However, on the EO1-Hyperion image we could identify few snow pixels in correspondence of north-west area of the volcano (Figure 6(b)). A reflectance spectrum obtained by averaging 21 Hyperion snow-ice pixels, was smoothed in order to reduce the noise.

We compared the reflectance spectra plots for different snow and ice surfaces [48] [49] with the in situ and Hyperion spectra. We noticed a correspondence between the glacier ice spectrum and the in situ one, and a good correspondence between the dirty glacier and the Hyperion spectra. The drop of reflectance, in the Hyperion spectrum, may be interpreted as the combination of dirty ice and melting effects in a $30 \mathrm{~m}$ pixel.

A good correspondence also in spectral features is observed. In particular we notice the same absorption feature at $450 \mathrm{~nm}, 780-800 \mathrm{~nm}, 900 \mathrm{~nm}$ and $1000 \mathrm{~nm}$ in both the Hyperion (Figure7(a)) and Hall spectra in Figure 7(b) [48] [49] highlighted by red arrows. In particular, the $1000 \mathrm{~nm}$ ice band is temperature dependent and it increase its absorption as more liquid water forms during the melting process [49].

The obtained result validates the procedure applied to derive the Hyperion reflectance, confirming that significant spectra can be obtained from EO1-Hyperion data after appropriate processing.

Spectral stability of the bands, in terms of spectral position, is also confirmed, since the reflectance of the melting snow spectrum has been retrieved and validated.

\section{Conclusions}

In field, reflectance measurements were conducted on Mt. Etna, aiming to provide a spectral characterization of lava flows. Reflectance spectra, representative of lava flows of different ages, have been generated. Although basalt rocks have low reflectance values and few characteristic bands in the VNIR range, we have found that their spectra are quite unique in their overall shape. Alteration due to the effects of lichens have been found in the 1652, 1992 and 1865 lava flows and follow the findings of previous studies [25].

In ground, reflectance has been compared against reflectance product (AST_07) generated by ASTER during on demand three visible bands possibly due by not including the aerosol types [44] in the reflectance ASTER product generation. In fact in SWIR range, where this effect is not dominant, a good agreement was found.

Regarding EO1-Hyperion spectra, the results of the comparison between in field and satellite show a good spectral correspondence (both VNIR and SWIR) demonstrating that the applied calibration and atmospheric correction procedure is reliable. In the VNIR, the error ranges between $2 \%$ and $8 \%$, while in the SWIR it is about $10 \%$ - 30\%. EO1-Hyperion shows a better spectral agreement with the ground truth compared to ASTER ones. However, the higher percentage error in the SWIR range compared to that one in the VNIR can be attributed to the low SNR of the EO1-Hyperion sensor (VNIR up 200 and SWIR $<100$ according to [47], which becomes predominant in the presence of a low reflectance target.

The obtained results validate the procedure we have applied to derive the EO1-Hyperion reflectance, confirming that significant spectra can be obtained from Hyperion data after appropriate processing and preferably for high reflectance target. 


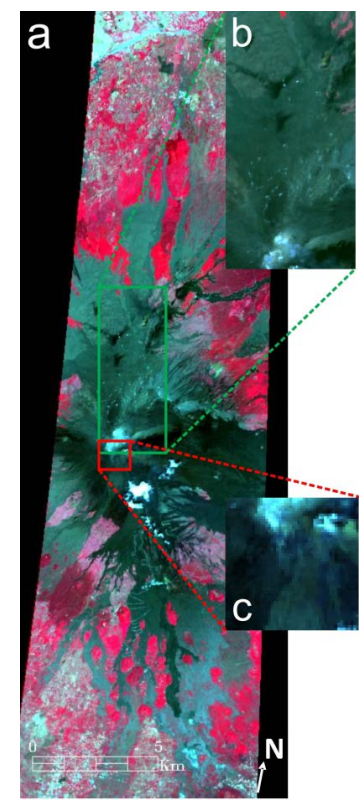

Figure 6. (a) EO1-Hyperion RGB colour composite visible channels acquired in July 2007; (b) The snow in the top crater area has melted, however in the north-west of the volcano (zoomed area b) few ice-snow pixels are detectable; (c) Zoomed area were the in ground reflectance for comparison (p18) was acquired.

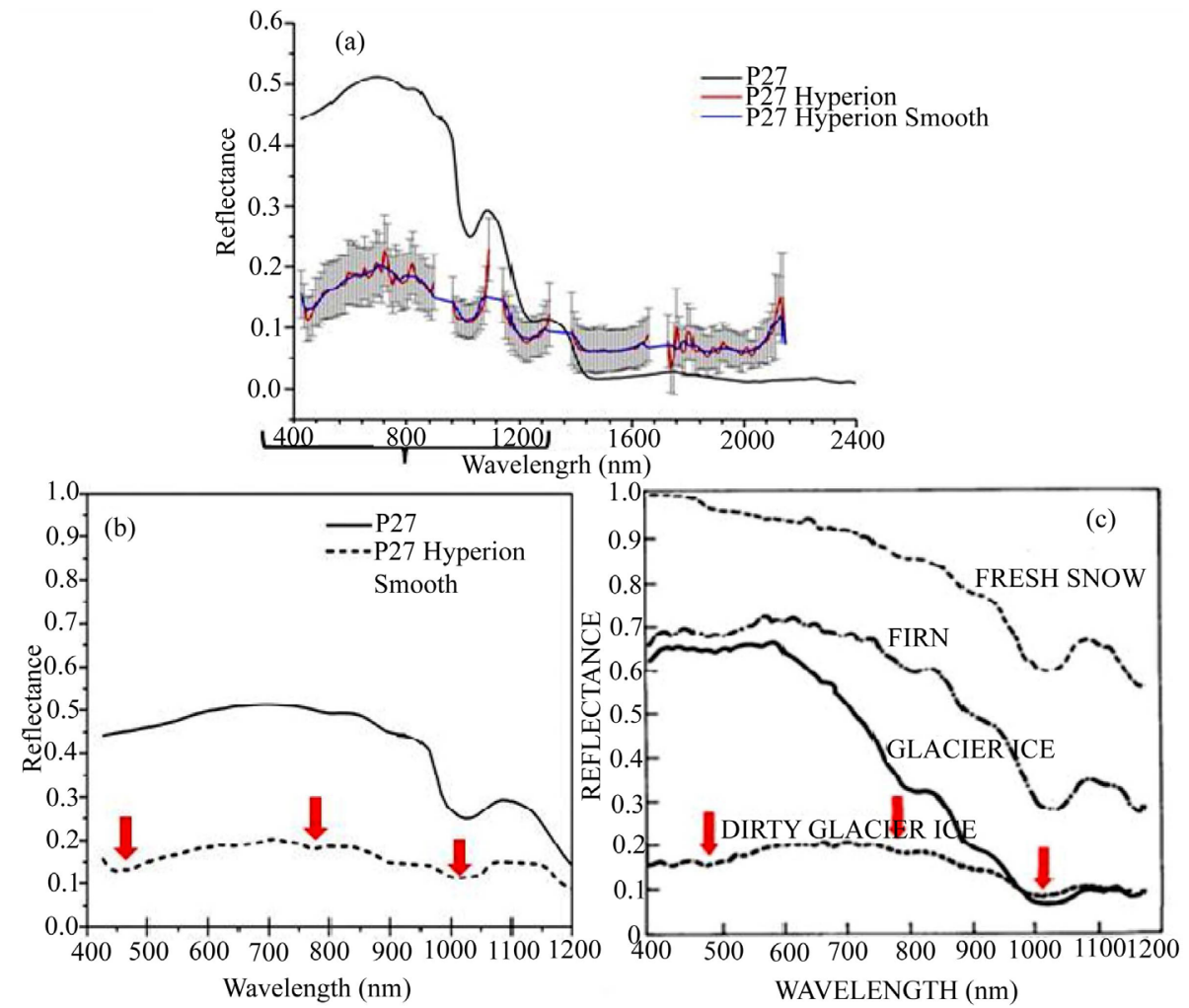

Figure 7. (a) in ground FieldSpec (p27, in black) ice-snow reflectance is plotted against EO1Hyperion average over 21 pixels (red) and smooted (blue). Hyperion snow-ice reflectance smoothed spectra are compared; (b) Zoom spectra in range between $400 \mathrm{~nm}$ and $1200 \mathrm{~nm}$ are plotted to be compared against (c) reflectance spectra for different snow types from [48]. Red arrows highlight the correspondence in absorption bands. 
Spectral stability of the bands, in terms of spectral position, has been confirmed, since the reflectance of the melting snow spectrum has been retrieved and compared against on ground (ice-snow, p27).

On ground reflectance measurements of volcanic area are hard to realize due to the extreme environment and few have been realized in the past [7] [25].

The spectral dataset generated during the fieldwork is so very valuable, and will be part of a spectral library project carried out by Istituto Nazionale di Geofisica e Vulcan logia for the Italian Space Agency (ASI) in the frame of the PRISMA Hiperspectral mission. Furthermore, there is an international growing interest in this such of measurement because of they may be used as planetary analogues, to identify minerals and composition from the data acquired by the numerous solar system spaceborne (e.g, Cassini, Rosetta, Bepi Colombo, etc.) missions which are equipped with hyper spectral sensors.

\section{Acknowledgements}

The authors thank D. Pieri, ASTER science Team Member, for the data acquisition planning support and the Jet Propulsion Laboratory, California Institute of Technology for providing ASTER imagery. We further thank the EO1 team for their free data policy, C. Carli for his support in the field measurements. We thank B. Behncke, A. La Spina and F. Murè (INGV Catania) for logistic support and assistance with their knowledge of the Mt. Etna area. A special thanks to Prof. Andrew Hardy for his English check.

\section{References}

[1] Clark, R.N. (1999) Chapter 1: Spectroscopy of Rocks and Minerals, and Principles of Spectroscopy. In: Rencz, A.N., Ed., Manual of Remote Sensing, Volume 3, Remote Sensing for the Earth Sciences, John Wiley and Sons, New York, 3-58.

[2] Hunt, G.R. (1997) Spectral Signatures of Particulate Materials in the Visible and near Infrared. Geophysics, 42, 501513. http://dx.doi.org/10.1190/1.1440721

[3] Madani, A.A. (2011) Spectral Properties of Carbonized Ultramafic Mantle Xenoliths and Their Host Olivine Basalts, Jabal Al Maqtal Basin, South Eastern Deserr, Egypt, Using ASD FieldSpec Spectroradiometer. The Egyptian Journal of Remote Sensing and Space Science, 14, 41-48.

[4] Amici, S., Piccioni, G., Coradini, A. and Solazzo, S. (2000) VIRTIS-M Laboratory Spectral Measurements of Analogues Cometary Samples. Planetary and Space Science, 48, 411-417.

[5] Capaccioni, F., Bellucci, G., Orosei, R. Amici, S., Bianchi, R., Blecka, M., Capria, M.T., Coradini, A., Erard, S., Fonti, S., Formisano, V., Forni, O., Mustard, J., Piccioni, G., Pieters, C., Poscolieri, M., Battistelli, E., Romoli, A., Digianpietro, M., Espinasse, S., Magnani, M. and Pasqui, C. (2001) MARS-IRMA: In-Situ Infrared Microscope Analysis of Martian Soil and Rock Sample. Advances in Space Research, 28, 1219-1224. http://dx.doi.org/10.1016/S0273-1177(01)00274-5

[6] Sgavetti, M. Pompilio, L. Roveria, M. Manzia, V., Valentino, G.M., Lugli, S., Carli, C., Amici, S., Marchese, F. and Lacava, T. (2009) Two Geologic Systems Providing Terrestrial Analogues for the Exploration of Sulfate Deposits on Mars: Initial Spectral Characterization. Planetary and Space Science, 57, 614-627.

[7] Amici, S., Piscini, A., Buongiorno, M.F. and Pieri, D. (2012) Geological Classification of Volcano Teide by Hyperspectral and Multispectral Satellite Data. International Journal of Remote Sensing, 34, 3356-3375. http://dx.doi.org/10.1080/01431161.2012.716913

[8] Goryniuk, M.C., Rivard, B.A. and Jones, B. (2004) The Reflectance Spectra of Opal-A (0.5 - 25 um) from the Taupo VolcanicZone: Spectra That May Identify Hydrothermal Systema on Planetary Surfaces. Geophysical Research Letters, 31, L24701. http://dx.doi.org/10.1029/2004GL021481

[9] De Angelis, S., De Sanctis, M.C., Ammannito, E., Altieri, F., Carli, C., Frigeri, A., Boccaccini, A. and Giardino, M. (2014) Analysis of Rocks Particulates by VNIR Spectroscopy with Ma_Miss Instrument Breadboard. 45th Lunar and Planetary Science Conference, The Woodlands, 17-21 March 2014, 1713.

[10] Amici, S. (2010) Calibration and Validation (CAL/VAL) of Remote Sensing Data and Spectral Characterization of Volcanic Rocks. PhD Thesis, University of Parma, Parma. http://dspace-unipr.cilea.it/bitstream/1889/1389/1/AmiciSPhD.pdf

[11] Pazand, K., Sarvestani, J.F., Reza, M. and Ravasan, S. (2013) Hydrothermal Alteration Mapping Using ASTER Data for Reconnaissance Porphyry Copper Mineralization in the Ahar Area, NW Iran. Journal of the Indian Society of Remote Sensing, 41, 379-389. http://dx.doi.org/10.1007/s12524-012-0229-0

[12] Pour, A.B. and Hashim, M. (2012) The Application of ASTER Remote Sensing Data to Porphyry Copper and Epi- 
thermal Gold Deposits. Ore Geology Reviews, 44, 1-9. http://dx.doi.org/10.1016/j.oregeorev.2011.09.009

[13] Honarmand, M., Ranjbar, H. and Shahabpour, J. (2013) Combined Use of ASTER and ALI Data for Hydrothermal Alteration Mapping in the Northwestern Part of the Kerman Magmatic Arc, Iran. International Journal of Remote Sensing, 34, 2023-2046. http://dx.doi.org/10.1080/01431161.2012.731540

[14] Millington, A.C. and Townshend, J.R.G. (1987) The Potential of Satellite Remote Sensing for Geomorphological Investigations: An Overview. In: Gardiner, V., Ed., International Geomorphology, Wiley, Chichester, 331-342.

[15] Thenkabail, P.S., Lyon, J.G. and Huete, A., Eds. (2012) Hyperspectral Remote Sensing of Vegetation. CRC Press, Boca Raton.

[16] Gomez, C., Rossel, R.A.V. and McBratney, A.B. (2008) Soil Organic Carbon Prediction by Hyperspectral Remote Sensing and Field Vis-NIR Spectroscopy: An Australian Case Study. Geoderma, 146, 403-411. http://dx.doi.org/10.1016/j.geoderma.2008.06.011

[17] Waldhoff, G., Bubenzer, O., Bolten, A., Koppe, W. and Bareth, G. (2008) Spectral Analysis of ASTER, Hyperion, and Quickbird Data for Geomorphological and Geological Research in Egypt (Dakhla Oasis, Western Desert). International Archives of the Photogrammetry, Remote Sensing and Spatial Information Sciences, 37, 1201-206.

[18] Taner San, B. and Lütfi Süzen, M. (2011) Evaluation of Cross-Track Illumination in EO-1 Hyperion Imagery for Lithological Mapping. International Journal of Remote Sensing, 32, 7873-7889. http://dx.doi.org/10.1080/01431161.2010.532175

[19] van der Meer, F.D., van der Werff, H.M.A., van Ruitenbeek, F.J.A., Hecker, C.A., Bakker, W.H., Noomen, M.F., van der Meijde, M., Carranza, E.J.M., de Smeth, J.B. and Woldai, T. (2012) Multi- and Hyperspectral Geologic Remote Sensing: A Review. International Journal of Applied Earth Observation and Geoinformation, 14, 112-128. http://dx.doi.org/10.1016/j.jag.2011.08.002

[20] Amici, S., Piscini, A., Buongiorno, M.F. and Pieri, D. (2013) Geological Classification of Volcano Teide by Hyperspectral and Multispectral Satellite Data. International Journal of Remote Sensing, 34, 3356-3375.

[21] Lentini, F. (1982) The Geology of the Mt. Etna Basement. In: Romano, R., Ed., Mount Etna Volcano, a Review of Recent Earth Sciences Studies, Mem. Soc. Geol. Ital., 23, 7-25.

[22] Lanzafame, G., Leonardi, A., Neri, M. and Rust, D. (1997) Late Overthrust of the Appenine-Maghrebian Chain at the NE periphery of Mt. Etna, Sicily. Comptes Rendus de l'Académie des Sciences Paris IIa, 324, 325-332.

[23] Neri, M., Mazzarini, F., Tarquini, S., Bisson, M., Isola, I., Behncke, B. and PareschiM, T. (2008) The Changing Face of Mount Etna's Summit Area Documented with Lidar Technology. Geophysical Research Letters, 35, Article ID: L09305. http://dx.doi.org/10.1029/2008GL033740

[24] Mazzarini, F., Favalli, M., Isola, I., Neri, M. and Pareschi, M.T. (2008) Surface Roughness of Pyroclastic Deposits at Mt. Etna by 3D Laser Scanning. Annals of Geophysics, 51, 813-822.

[25] Spinetti, C., Mazzarini, F., Casacchia, R., Colini, L., Neri, M., Behncke, B., Salvatori, R., Buongiorno, M.F. and Pareschi, M.T. (2009) Spectral Properties of Volcanic Materials from Hyperspectral Field and Satellite Data Compared with LiDAR Data at Mt. Etna. International Journal of Applied Earth Observation and Geoinformation, 11, 142-155. http://dx.doi.org/10.1016/j.jag.2009.01.001

[26] Behncke, B., Neri, M. and Nagay, A. (2005) Lava Flow Hazard at Mount Etna (Italy): New Data from a GIS-Based Study. Special Paper: Geological Society of America, 396, 187-205.

[27] Behncke, B., Calvari, S., Giammanco, S., Neri, M. and Pinkerton, H. (2008) Pyroclastic Density Currents Resulting from Interaction of Basaltic Magma with Hydrothermally Altered Rock: An Example from the 2006 Summit Eruptions of Mount Etna, Italy. Bulletin of Volcanology, 70, 1249-1268.

[28] Neri, M., Acocella, V., Behncke, B., Giammanco, S., Mazzarini, F. and Rust, D. (2011) Structural Analysis of the Eruptive Fissures at Mount Etna (Italy). Annales Geophysicae, 54, 464-479.

[29] Hatchell, D.C. (1999) ASD Technical Guide. 3rd Edition, Analytical Spectral Devices Inc, Boulder.

[30] Musacchio, M., Amici, S., Teggi, S., Pompilio, L., Sgavetti, M. and Buongiorno, M.F. (2007) Una nuova procedura per le correzioni atmosferiche: Applicazione sulla solfatara di Pozzuoli. Rivista Italiana di Telerilevamento, 39, 77-86.

[31] Brailley, B. (2007) ASTER Data Products: Generation Characteristics and Access. AIT-2007, 39, $19-31$.

[32] Fuijisada, H. (1995) Design and Performance of ASTER Instrument. Proceedings of SPIE, 2583. http://dx.doi.org/10.1117/12.228565

[33] Abrams, M. (2000) The Advanced Spaceborne Thermal Emission and Reflectance Radiometer (ASTER) Data Products for the High Spatial Resolution Imager on NASA's Terra Platform. International Journal of Remote Sensing, 21, 847-859.

[34] Yamaguchi, Y., Kahake, A.B., Tsu, H., Kawakami, T. and Pniel, M. (1998) Overview of the Advanced Spaceborne 
Thermal Emission and Reflectance Radiometer (ASTER). IEEE Transactions on Geoscience and Remote Sensing, 36 1062-1071. http://dx.doi.org/10.1109/36.700991

[35] Pieri, D.C. and Abrams, M.J. (2004) ASTER Watches the World's Volcanoes: A New Paradigm for Volcanological Observations from Orbit. Journal of Volcanology and Geothermal Research, 135, 13-28. http://dx.doi.org/10.1016/j.jvolgeores.2003.12.018

[36] Fujisada, H. (1998) ASTER Level-1 Data Processing Algorithm. IEEE Transactions on Geoscience and Remote Sensing, 36, 1101-1112. http://dx.doi.org/10.1109/36.700994

[37] Kieffer, H.H., Mullins, K.F. and MacKinnon, D.J. (2008) Validation of the ASTER Instrument Level 1A Scene Geometry. Photogrammetric Engineering \& Remote Sensing, 74, 289-301. http://dx.doi.org/10.14358/PERS.74.3.289

[38] Bailey, G.B. (2007) ASTER Data and Products: Generation, Characteristics, and Access. Rivista Italiana di Telerilevamento, 39, 19-31.

[39] Barry, P.S., Jarecke, P., Pearlman, J., Jupp, D.L.B., Lovell, J. and Campbell, S. (2002) Radiometric Calibration Validation of the Hyperion Instrument Using “In Situ Truth" at a Site in Lake Frome. Proceedings of SPIE, 4480, 242-246. http://dx.doi.org/10.1117/12.453346

[40] Biggar, S.F., Thome, K.J. and Wisniewski, W. (2003) Vicarious Radiometric Calibration of EO-1 Sensors by Reference to High-Reflectance Ground Targets. IEEE Transactions on Geoscience and Remote Sensing, 41, 1174-1179. http://dx.doi.org/10.1109/TGRS.2003.813211

[41] EO1-User Guide (2004) http://eo1.usgs.gov/documents/EO1userguidev2pt320030715UC.pdf.

[42] FLAASH Atmosferic Correction Module, EXELIS, 2004. http://www.exelisvis.com/portals/0/pdfs/envi/Flaash_Module.pdf

[43] Sgavetti, M., Pompilio, L. and Meli, S. (2006) Reflectance Spectroscopy (0.3-2.5micron) at Various Scales for Bulk-Rock Identification. Geosphere, 2, 142-160. http://dx.doi.org/10.1130/GES00039.1

[44] Bergstrom, R.W., Pilewskie, P., Russell, P.B., Redemann, J., Bond, T.C., Quinn, P.K. and Sierau, B. (2007) Spectral Absorption Properties of Atmospheric Aerosols. Atmospheric Chemistry and Physics, 7, 5937-5943. http://dx.doi.org/10.5194/acp-7-5937-2007

[45] Abrams, M., Hook, S. and Ramachandran, B. (2002) ASTER User Handbook, v2: Advanced Spaceborne Thermal Emission and Reflection Radiometer. Jet Propulsion Laboratory, Pasadena.

[46] Mauer, J. (2002) Retrieval of Surface Albedo from Space. http://www2.hawaii.edu/ jmaurer/albedo/.

[47] Kruse, F.A., Boardman, J.W., Huntington, J.F., Mason, P. and Quigley, M.A. (2002) Evaluation and Validation of EO1 Hyperion for Geologic Mapping. IGARSS 2002, 24-28 June 2002, Toronto.

[48] Hall, D.K. and Martinec, J. (1985) Remote Sensing of Ice and Snow. Chapman and Hall, New York, 189.

[49] Clark, R.N. (1981) Water Frost and Ice: The Near-Infrared Spectral Reflectance 0.65-2.5 $\mu$ m. Journal of Geophysical Research, 86, 3087-3096. http://dx.doi.org/10.1029/JB086iB04p03087 
Scientific Research Publishing (SCIRP) is one of the largest Open Access journal publishers. It is currently publishing more than 200 open access, online, peer-reviewed journals covering a wide range of academic disciplines. SCIRP serves the worldwide academic communities and contributes to the progress and application of science with its publication.

Other selected journals from SCIRP are listed as below. Submit your manuscript to us via either submit@scirp.org or Online Submission Portal.
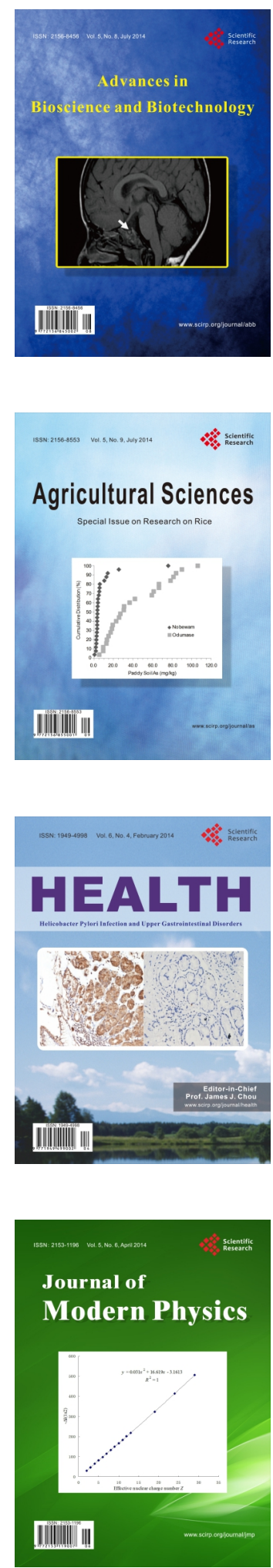
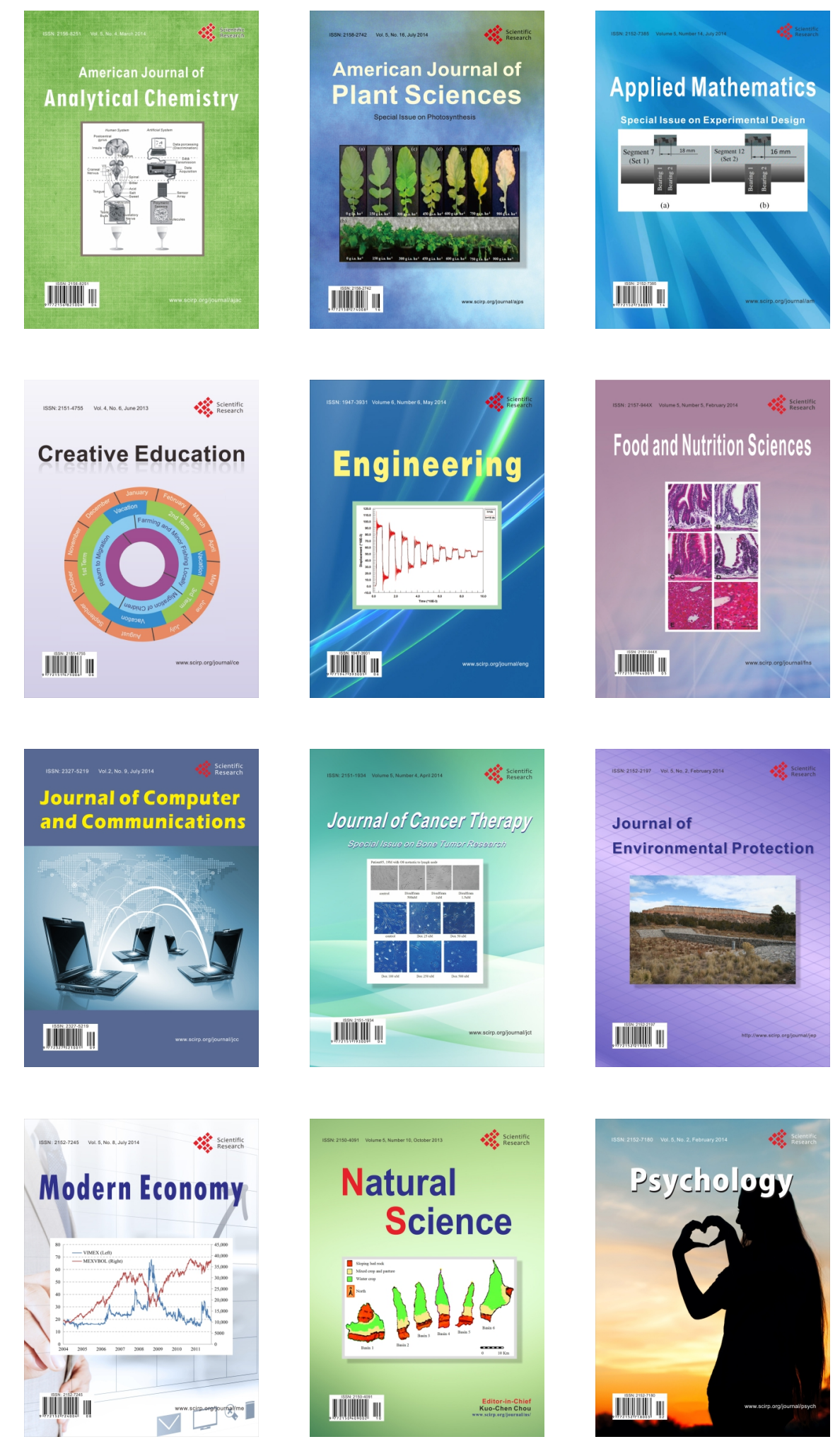